\title{
A Critical Study on Demolition Construction Waste as Partial Substitute of Fine Aggregates in Green Concrete
}

\author{
Sachin Sharma ${ }^{*}$, Priyanka Pandey ${ }^{2}$, Rakesh Bhandari ${ }^{3}$, Abhay M. Shende ${ }^{4}$ and Anju \\ Sharma ${ }^{5}$ \\ ${ }^{1 *}$ Research Scholar, Department of Civil Engineering, Sangam University, Bhilwara, India \\ ${ }^{2}$ Assistant Professor, Department of Civil Engineering, Sangam University, Bhilwara, India \\ ${ }^{3}$ Associate Professor and Dy. Dean, Department of Research, Sangam University, Bhilwara, India \\ ${ }^{4}$ Principal, Priyadarshini J. L. College of Engineering, Nagpur, India \\ ${ }^{5}$ Professor, Department of Civil Engineering, Aravali Institute of Technical Studies, Udaipur, India
}

\section{Corresponding Author: sachin2410s@gmail.com}

\begin{abstract}
In this rising of the world because of more interest of normally accessible growing materials for the need of modification of development material. Concrete is of growing importance than any other building material on the planet. Because of the increase in population, the volume and kind of waste materials in the globe is increasing every day. As a result, many more non-perishable materials are available in the environment. The DC waste materials have extended due to disposal extremity in the world and thereby contributing to the environmental problems. Demolition is a term that is used to describe the act of demolishing anything. Construction waste materials have indeed been disposed of in concrete safely and cost-effectively. The use of DC waste materials as a partial replacement for fine aggregates in the creation of ecologically friendly concrete is proposed in this study.
\end{abstract}

Keywords: Concrete; Compressive Strength; Demolition Waste; Fine Aggregates;

\section{Introduction}

Demolition Construction Waste (DC Waste) is founded from repair \& renovation, Demolition \& Construction of houses \& Garages, Large commercial Building, Bridges, Highways, and Dams. DC waste is comprised of Concrete, Soil, Steel, wood, 
and plastic, and different materials - blocks and mortar.The core reason for its workability, high strength, and Durability. Every year, one tonne of concrete is used for every living human on the planet. The construction of infrastructure development in India, such as airports, highways, thermal plants, dams, and bridges, is increasing every year as a result of globalization [1]. The significance of C\&D waste management is not lost among the stakeholders particularly in large cities, where impacts have already been felt. But still, the effectual management of C\&D waste is held back by numerous challenges and performance is far from ideal [2]. A huge amount of waste material is produced per annum in all worlds, DC waste contributes the maximum percentage of about $75 \%$. Moreover, ceramic waste material gives more percentage of wastes within DC wastes about 54\% [6]. With the fast growth in construction actions of India, it is appropriate the creation of DC waste with the expansion of the construction industry and various connected issues.

Demolition waste of more established designs for endorsement of new development and ongoing construction for additionally expanding need of reassuring prompts the development of the volume of DC waste because of quick urbanization in city and towns. The environmental laws had required aggregates plants to go for the substitution of DC waste, which is approx $75 \%$ of the whole DC waste [5]. The building area assessment method considers the different stages of DC waste production from the perspective of construction, renovation, maintenance, demolition, and decoration of building structures and becomes the conventional process for estimating construction waste. DC wastes products can be performed using various gray models, linear regression moving average model. 


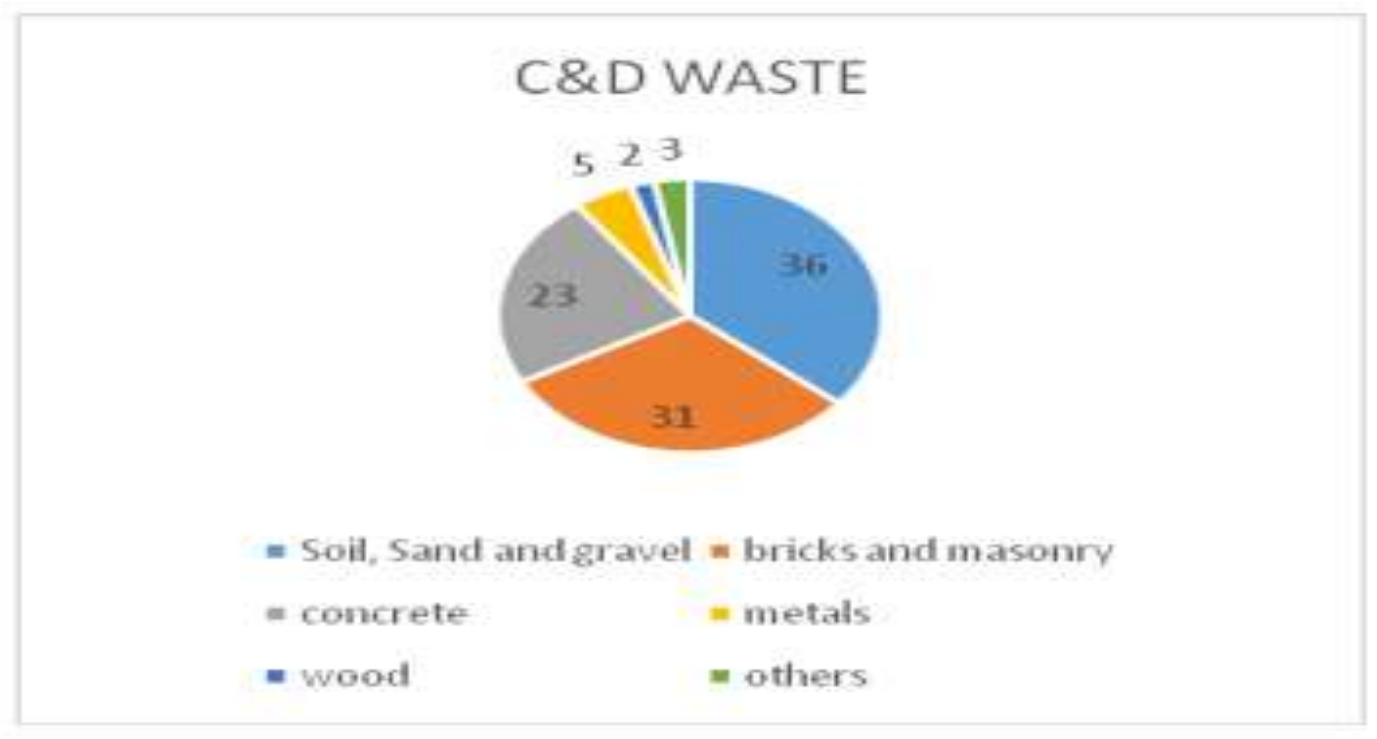

Figure 1. Different C\&D Waste in World Production [2]

\section{Critical Literature Review}

Waste administration is not just a money problem; recycling and reuse of waste materials cannot save money, but also create wide-ranging environmental profits, with natural resources. Recycle and wastes anticipation reduces the water and air pollutionrelated to DC waste materials built-up and transportation. This protects energies and decreases associated greenhouse production. The recycling of many various materials needs low energy than production from virgin stock materials.

Manjari Bhattacharya et al. (2019) studied the waste materials like DC waste utilized in plain concrete and their assets on various properties of cement. M30 grade of mix design of concrete has been used. Thirty-six portions were tested, with fine and coarse aggregate being replaced with ceramics waste powder and DC waste at intervals of $10 \%$ from $0 \%$ to $60 \%$. Fine aggregate, coarse aggregate, and alternative materials have all been tested for water absorption and specific gravity. Around Rs. 523/- was saved by replacing 50\% of DC waste with fine and coarse aggregates in $1 \mathrm{~m} 3$ concrete without influencing the compressive strength of the modified concrete. In modified concrete, Ceramic wastes could be utilized as replaced and extra 
materials. Approx 50\% is the ideal substitution proportion of fine and coarse aggregates with DC waste [1].

Md. Omar Ali Mondal (2018) As per studies this literature to check the various property of concrete b/w natural brick aggregates and recycled brick aggregates concrete by disbursing an altered percentage of Blast furnace slag, superplasticizers, and fly ash were used to improve the Modified concrete's durability. The compressive strength was found to be $21.81,24.52$, and $25.30 \mathrm{MPa}$, at 28 days [8] respectively, by replacing $10 \%, 15 \%$, and $20 \%$ blast furnace slag with salvaged brick aggregate. The compressive strength was improved at 60 days but reduced at 28 days slowly by the median percentage of fly ash for various intervals of 5\% from $10 \%$ to $35 \%$ with salvaged brick aggregate. At 28 days, water and fast chloride permeability were lowered when compressive strength was increased [3].

Rachit Sharma (2017) This study Shows decent results on DC waste or glass waste powder used in concrete with or without the inclusion of fiber and superplasticizer. The compressive strengths of modified concrete using DC waste by substitution of fine aggregates get a decent outcome. When fine aggregates are replaced with DC waste to varying degrees of 30 percent, the compressive strength of modified concrete is increased.

The substitute of fine aggregates with glass waste powder utilizing superplasticizer and fiber will tend to more growth compressive strength of design concrete. Nevertheless, if DC waste aggregates and glass waste powder substitutes to the fine aggregates adding fiber and superplasticizer utilized, the low compressive strength is accomplished. The DC waste and glass waste powder has utilized in concrete have improved compressive strengths, thereby solving the issue of removal just as safeguarding the environment [4].

Saswat Hota et al. (2016) Involved the strength properties (flexural and compressive strength) as well as the waste of demolition and ceramic percentages as fractional additions of fine aggregates in an experiment. During this study, M25 grade concrete having materials have range was 1:1.25:2.5 and 1:1.5:3 with wlc proportion of 0.46 is utilized as a base. By weight of cement observance dose of superplasticizer was $0.3 \%$ 
individually. Fine aggregate can be kept while casting rigid pavement by using ceramic and demolition waste $40 \%$ regular. Compressive strength of up to $20 \%$ demolition waste and $20 \%$ ceramic waste is higher than transfer concrete [5].

Shruthi H. G et al. (2016) An experimental investigation was carried out on the use of ceramic tile wastes in concrete to be a substitute for regular coarse aggregate, with a range of $0 \%, 10 \%, 20 \%$, and $30 \%$ of the replacement and M20 grade concrete being cast. The concrete molds were cast and evaluated for Compressive Strength and Split Rigidity after 3, 7, and 28 days. While $30 \%$ of Ceramic tile aggregates waste was substituted with coarse aggregates, the Split tensile strength was set up remarkably. The compressive strength and split tensile strength of $10 \%$ and $20 \%$ supplementary of CTA isn't improved. There start a little distinction in the all strength of CTA Concrete, when contrasted and insignificant concrete. The ideal maximum outcome is observed for $30 \%$ supplanting of CTA with coarse aggregate [6].

Md. Monish et al. (2013) The effect of adding coarse aggregates from demolition debris on the workability and mechanical properties of reused concrete at the end of 7 and 28 days is investigated. The compressive strength of demolition utilized concrete recognized was connected with regular concrete. The compressive strength of modified green concrete till $30 \%$ CA assistant with crushed waste at the end of 28 days was related to being recognized with ordinary concrete, according to test results. Cubical specimens were cast to define the compressive strength of design concrete and observed values of strength are presented in the range of approx 86-95\% for recycled concrete mix [7].

\section{Conclusions}

- According to various literature reviews, we achieved optimum compression strength of design concrete, when $30 \%$ of Ceramic Tiles waste was replaced by coarse aggregate.

- Approx 500/- Rupees saved in 50\% replacement of DC waste if we used Concrete with fine and coarse aggregates required compressive strength of DC waste concrete. 
- The compressive strength of green concrete average $20 \mathrm{MPa}-24 \mathrm{MPa}$, respectively by recycled and natural brick aggregates at 28 days.

- When up to $20 \%$ DC waste is utilized in concrete, the compressive strength is higher than nominal concrete.

- Compressive Strength was improved, according to the literature review. Concrete with an optimum 30 percentage of substitution of coarse recycled aggregates powder was compared to ordinary concrete.

\section{Conflicts of Interest}

The authors declare no conflict of interest.

\section{References}

[1] Manjari Bhattacharya, Javed Shaikh, Avinash More, Priyanka Ghase, Hamza Mulla, "Experimental Analysis of Concrete Using Ceramic Tile Powder and Demolition Waste”. International Journal of Engineering Development and Research (IJEDR) Vol. 7, Issue 3, pp.10-12, 2019.

[2] A. Naveen Arasu, M. Muhammed Rafsal, O.R.Surya K, "Experimental Investigation Of High Performance Concrete By Partial Replacement of Fine Aggregate By Construction Demolition Waste”. International Journal of Scientific \& Engineering Research (IJSER) Vol. 9, Issue 3, pp. 47-52, 2018.

[3] Md. Omar Ali Mondal, Md. All Mokadim, and Abu Zakir Morshed, "Use Of Supplementary Cementitious Materials In Recycled Brick Aggregate Concrete". Proceedings of the 4th International Conference on Civil Engineering for Sustainable Development (ICCESD) ICCESD (4356) pp. 1-12, 2018.

[4] Rachit Sharma, "Compressive Strength of Concrete Using Construction Demolition Waste and Glass Waste, Superplasticizer and Fiber”. Jordan Journal of Civil Engineering, Vol.11, No. 3, 2017.

[5] Saswat Hota and Vikas Srivastava, "Partial Replacement of Fine Aggregate with Ceramic and Demolition Waste in Rigid Pavement". International Journal of Innovative Research in Science, Engineering, and Technology (IJIRSET) Vol. 8, Issue 5, pp. 15141-15151, 2016.

[6] Prof. Shruthi. H. G, Prof. Gowtham Prasad. M. E, Samreen Taj, and Syed Ruman P, "Reuse of Ceramic Waste as Aggregate in Concrete". International Research Journal of Engineering and Technology (IRJET) Vol. 3, Issue 7, pp.115-119, 2016.

[7] Mohd Monish, Vikas Srivastava, V.C. Agarwal, P.K. Mehta, and Rakesh Kumar, "Demolished waste as coarse aggregate in concrete”. J. Acad. Indus. Res. Vol. 1(9) pp. 540-542, 2013.

[8] IS 456-2000: Plain and Reinforced concrete, Bureau of Indian Standards, (BIS), New Delhi.

[9] IS 10262-2009: Recommended guidelines for concrete mix design, Bureau of Indian Standards (BIS), New Delhi 